\title{
Erratum to: The Assessment of the Spinal Curvatures in the Sagittal Plane of Children Using an Ultrasound-Based Motion Analysing System
}

\author{
Mária Takács, ${ }^{1}$ Ervin Rudner, ${ }^{1}$ Attila Kovács, ${ }^{2}$ Zsanett Orlovits, ${ }^{3}$ and Rita M. Kiss ${ }^{4}$
}

${ }^{1}$ MÁV Hospital Department of Orthopaedics, Verseghy Street 6-8, 5000 Szolnok, Hungary; ${ }^{2}$ MÁV Hospital Department of Rheumatology, Verseghy Street 6-8, 5000 Szolnok, Hungary; ${ }^{3}$ Institute of Mathematics, Budapest University of Technology and Economics, Egry József Street 1, 1111 Budapest, Hungary; and ${ }^{4}$ Cooperation Research Center for Biomechanics, Department of Mechatronics, Optics and Mechanical Engineering Informatics, Budapest University of Technology and Economics, Müegyetem Rkp. 3-9, 1111 Budapest, Hungary

Erratum to: Annals of Biomedical Engineering (2014) DOI: $10.1007 / \mathrm{s} 10439-014-1160-z$

The Acknowledgment Section was omitted from the article. The Acknowledgment section's text is the following:

\section{ACKNOWLEDGMENTS}

The researchers were supported by OTKA K75018 researches. The authors would like to say thank you to Ildikó Nagy and Gábor Szabó physiotherapists for their invaluable assistance in the performance of the measurements.

Address correspondence to Mária Takács, MÁV Hospital Department of Orthopaedics, Verseghy Street 6-8, 5000 Szolnok, Hungary. Electronic mails: drtakacsmaria@freemail.hu, dr.kovacs. attila.phd@gmail.com, orlovits@math.bme.hu and kissrit@ t-online.hu

The online version of the original article can be found under doi: 10.1007/s10439-014-1160-z. 